\title{
Validity and Reliability of Assessment of Language-Related Functional Activities (ALFA): Evidence from Arab Aphasics
}

\author{
Sadeq Ali Saad Al Yaari (Corresponding author) \\ Independent Researcher, Dept. of English, College of Arts, King Saud University (KSU) \\ Riyadh, Kingdom of Saudi Arabia \\ E-mail: prof.sadeq@gmail.com
}

\begin{abstract}
Nassr Almaflehi
A professor of Statistics, College of Applied Medical Sciences, King Saud University (KSU)

Riyadh, Kingdom of Saudi Arabia

E-mail: nassr_almaflehi@hotmail.com
\end{abstract}

Received: October 28, 2013 Accepted: November 10, 2013 Published: December 12, 2013

doi:10.5296/jsel.v1i2.4739 URL: http://dx.doi.org/10.5296/jsel.v1i2.4739

\begin{abstract}
Background: Assessment of language-related functional activities (ALFA) is of vital importance in assessing aphasics' performance of both sexes. However, the validity and reliability of this language therapeutic test has never been validated in the Arabic medical literature.

Purpose: The aim of this study was to validate the test by assessing the language-related functional activities of 100 gender aphasics based in a medical faculty.

Design: ALFA Pre-and-posttest was administered twice in three weeks to test the language-related functional activities of 100 gender aphasics.

Settings: Al Khars hospital in Al Ahsa'a, Kingdom of Saudi Arabia (KSA).

Participants: Sixteen to eight-year-old participants $(\mathrm{N}=100$ men and women) were enrolled in this experiment. Again, the purpose was to assess their language-related functional activities using ALFA.
\end{abstract}


Procedures: The first step was to translate the English version of ALFA test into the mother tongue of the patients (Arabic). Secondly, the translated text is reviewed and edited by three specialists of Arabic language. Having the test standardized, the third step was to assess language-related functional activities of the participants in natural environment. Assessment took place in three weeks. In the first week, a pre-test was administered to the participants at hand and after two weeks, a post-test was administered to identify whether or not significant differences between the two tests (pre-and-posttest) could be observed.

Interventions: Outcomes of the results obtained from the analyses were broadly discussed. Linguistic and statistical comparisons were held to illustrate the findings of this study.

Main outcomes and Results: The analysis of the obtained results indicated that the performance of the aphasic participants in the post-test did not differ from that of the pre-test (, respectively).

Conclusions \& Implications: ALFA was proved to be a valid and reliable test. Moreover, outlined results pointed out the importance of assessing not only gender aphasics' language, but also their language-related functional activities. Further research is needed to explore how gender aphasics' verbal and non-verbal performances interact.

Keywords: ALFA, language test, Arab aphasics, validity, reliability, psychoneurolinguistics

\section{Introduction Chapter}

\subsection{Introduction}

Increasing number of assessment tools, notably those relating to adults throughout the world have created an urgent need for intensive investigations and strategies that clinicians and speech language Pathologists/ Therapists (SLP/Ts) use to meet the highest standards and criteria of diagnosis. For example, research has shown that stacked-wave-V auditory brainstem response (ABR) requires a masking technique that may not be readily available to the clinician. Moreover, relatively high-level noise is required and may be annoying to the patient requires a masking technique that may not be readily available to the clinician. Since the only alternative choice was tone-bursts assessment tool, there was a need for more research to compare the merits and demerits of the two tools. Philibert, et al., (2003) have undertaken a comparative study between the two assessment tools. The overall objective of the researcher was "to explore a possible alternative approach, particularly one that might be both more accessible to the clinician, regardless of evoked potential test instrument used, and perhaps more acceptable to the patient." (Philibert, et al., 2003:p.2)

Neuropsycholinguistically speaking, aphasia refers to language disorders marked by impairments in language abilities and communication skills, and is associated with cognitive impairment and deficits in adaptive functioning. Evaluative tests have consistently demonstrated that aphasics with language impairments have deficits in both language areas and cognitive motor. Attempting to examine the validity and reliability of them, Brogden (2008) undertakes a study on the tests administered for aphasics to identify to what extent 
these tests could be used to test gender. Cross-sectional design and five dynamic indicators of basic early literacy skills measures have been identified as two valid assessment tools to test oral reading fluency in both sexes (Below, et al., 2010).

Is dysphagia short questionnaire (DSQ) valid or not? Today it is widely believed, among the neuropsycholinguists, SLP/Ts and experts alike, that the questionnaire of the aphasics is linked with better knowledge of aphasia's type (Skeppholm, et al., 2012). Is this notion correct or yet another stereotype? To address this question, the validity of DSQ, as assessed by SLP/Ts, is considered. A new perspective was taken in this research by controlling for age, which is one of the principal psychoneurolinguistic characteristics that interacts with the questionnaire itself, in order to clarify how it affects the diagnosis process. The DSQ was constructed in collaboration with a group of ear-nose-and-throat specialists. In a first validation study, 45 patients with stationary dysphagia for various reasons completed the DSQ twice 2 weeks apart. To evaluate the utility of the DSQ, a second validation study was performed, where 111 subjects undergoing anterior cervical spine surgery for degenerative disk disease completed the form preoperatively and at 4 weeks, 3 months, and 1 year after surgery. Results initially reported that the DSQ is considered a validated tool for the assessment of dysphagia in anterior cervical spine surgery patients.

Hurkmans, et al., (2012)'s experiment investigated whether or not modified diadochokinesis test has a strong internal consistency and adequate psychometric properties. Outlined results show that the test can be used to measure changes in speech motor control during treatment for apraxia of speech. Again, the aim of Marshall, et al., (2012)'s study was to in/validate a new technique designed for assessing and evaluating aphasics with different types of language deficits. The findings indicate a positive interaction and response to the new technique which conform its validity and reliability.

The validity and reliability of stroke aphasic depression questionnaire (SADQ) to assess aphasics of both sexes was also investigated. The new technique has been used to assess a165 aphasics of both sexes and is found to be a valid and reliable observational screening measure of depressive symptoms for stroke patients with aphasia (Cobley, et al., 2012). The researchers recommend the test, not only for aphasics, but also "for identifying patients who require further evaluation." (Cobley, et al., 2012: p.373)

Attard, et al., (2013) compare the validity and the reliability of two evaluative techniques, namely constraint-induced aphasia therapy-plus and multi-modality aphasia therapy to identify to what extent they assess aphasics' language abilities. The research team found that both techniques can be used as means of evaluating aphasics' linguistic abilities. Another experimental study examined reliability and validity of Dutch version of the life satisfaction questionnaire is undertaken by Boonstra, et al., (2012). The team used the test to assess 159 adult aphasics (over 18 years of age). Results of the team show that unlike the discriminate validity of the test which was good, the test's reliability was moderate.

Aphasics' language-related functions and communication skills were assessed by trail making test. Allen, et al., (2012) who aim to measure the reliability and validity of the test, administered it for the first time to assess 242 aphasics (121 with sustained TBI and 121 
normal control participants). Findings demonstrate that the comprehensive trail making test is sensitive to TBI and overall demonstrates classification rates that are comparable with some other versions of the test. In developing a test of language-related functions and communication skills for aphasics, the focus is usually on the reliability and validity of the test that will make the test usable. Examining the validity and reliability of the national institutes of health stroke scale, Okubo, et al, (2012) used the scale to assess 50 adult aphasics of both sexes (range 26-91 years). According to Okubo and his colleagues, the scale is highly sensitive (88\%) and specific (85\%) in detecting language impairments.

The study of von Steinbuechel, et al., (2012) employed the measures of global assessment to examine a 6-item QOLIBRI overall scale, and identify whether or not it could provide an index of HRQoL after traumatic brain injury (TBI). Seven hundreds and ninety-two subjects with TBI were included in the study, matched for age, education level and intelligence quotient (IQ), but not for language (6 different languages). Results show that the reliability of the QOLIBRI-OS was good and similar in participants with higher and lower cognitive performance. Factor analysis indicated that the scale is uni-dimensional. Additionally, the findings indicate a satisfactory fit with this model. The QOLIBRI-OS, according to the research analysis, correlates highly with the total score from the full QOLIBRI scale $(r=0.87)$. Furthermore, moderate to strong relationships were found among the QOLIBRI-OS and the extended Glasgow outcome scale, short-form-36, and hospital anxiety and depression scale $(\mathrm{r}=0.54$ to -0.76$)$. Such outcomes demonstrate that the QOLIBRI-OS showed good construct validity in the TBI group. Functional connectivity stability was found in the results. These results underline the importance of the QOLIBRI-OS as a means through which clinicians, $\mathrm{SLP} / \mathrm{Ts}$ and experts in the field can easily assesses a similar construct to the QOLIBRI total score and can be used as a brief index of HRQoL for TBI. Moreover, the study requires further investigation in larger and longitudinal studies.

Traditionally, validation research focusing on the brain included only one age group. Recently, inclusion of multiple -based group research has shown that significant differences in age groups contribute to unique profiles of cognitive, emotional, and neuropsychological dysfunction, as well as dimorphic patterns of structural brain damage and recovery. The study of Sadeq et al., (2013) employed ABR of 30 Arab infants with different auditory impairments and demographically-similar number of children participants to explore the validity and reliability of ABR to measure hearing problems in both Arab infants and children. Qualitative and statistical analyses revealed that ABR is valid and reliable when measuring Arab infants and children suffering from hearing problems.

\subsection{Aims of the Study}

A low/ high level of response to assessment of language- related functional activities (ALFA) and other assessment tools is a mentally influenced phenotype that predicts later aphasics' performance in language-related activities. While the low/high scores reflect, at least in part, a low/high brain response to ALFA, the psychoneurolinguistic underpinnings of the validity and reliability of English versions of ALFA have only recently been addressed. Here, we used Arabic version of ALFA on 100 Arab subjects, to test the validity and reliability of this test. 
Specifically, the study aims to answer the following questions:

1. Can ALFA test what it is supposed to test?

2. Are the results obtained from the analysis of ALFA pre-and-posttest the same or at least similar? To what extent these results are significantly the same/ different in light of gender differences?

\subsection{Methodology}

One of the two researchers took part in administering ALFA pre-and-posttest sessions to 100 gender aphasics (50 male and 50 females) who receive their therapeutic treatment at Al Khars hospital in Al Ahsa'a city, Kingdom of Saudi Arabia (KSA). The age of the participants ranges between 16 and 65 years old. The analysis was performed in several steps. The test was translated into Arabic language and Arabic translated version was standardized by three Arabic language specialists. The Arabic version of the ALFA was then presented in the first week as (a pre-test) to the participating aphasics who responded to the tester's questions and instructions. After 21 days (3 weeks), a second test (posttest) was given to the same participants. Examiner record booklets and patients' response booklets were then collected. The data were analyzed using qualitative and statistic content analyses. The researchers performed independent preliminary analyses, which were further developed and intensively discussed between them.

\section{Analysis}

\subsection{Validity of ALFA (Arabic version)}

There is an increasing interest to in/validate language tests for characterizing spatial and temporal aspects of cortical processing and measuring the degree to which evidence and theory support the interpretations of test scores entailed by proposed uses of tests. However, a valid test normally tests what it is supposed to test (what it was designed for). In order to dis/ prove that, one has to examine the subjects as well as the questions of the tests. Consider:

\subsubsection{ALFA Main Subjects}

ALFA main subjects are focused on the following issues:

1. Telling time.

2. Counting money.

3. Addressing an envelope.

4. Solving daily math problem.

5. Writing a check and balancing a checkbook.

6. Understanding medicine labels.

7. Using a calendar.

8. Reading instructions. 
9. Using the telephone.

10. Writing a phone message.

Psychoneurolinguistically speaking, these topics deal with daily life's issues. Moreover, they are investigating language-relating functional activities that aphasics do in their everyday life. For example, telling time requires both comprehension and production. Comprehending questions and requests including: What time is it? Time please? Excuse me; do you mind tell me what time is it now?, etc. It also requires understanding times, time adverbs, hours, and numbers and this is relating to other questions including those of counting and/ or calculating. This is evidence that all questions are linked to each other. Taken together, they deal with linguistic disorders like Broca's aphasia, Wernicke's aphasia, dysgraphia/ agraphia, dyslexia/alexia, dyscalculia, anomia and ao forth.

\subsubsection{ALFA Questions}

ALFA questions, as the name implies, question the aphasic patient about the language-related functional activities and this was the strategy of the designers from the first edition of the test. The added questions in the following editions and versions made this viewpoint practical. Specifically for questions that require the patient to practice something (move one of his organs like mouth, hand, etc.), the effect of the questions on the patients' response was remarkably nonlinear. Therefore, we used the single-subject responses to construct data analysis and obtained notably higher sensitivity natural answers than with conventional stimulus-based programmed results. Such viewpoint can be clearly explained in light of the ALFA questions themselves in the examiner's manual. Consider:

(ماري وبيرون بارنز), 'Mary and Byron Barnes.'

(2912),'2912 Honeycreek Rd.'

) (ولاية شيكاغو), 'Chicago.'

(مدينة إلينوى), 'Illinois.'

(60626), ‘60626.'

The above mentioned address is an example given by the designers. Now, let us see how the analysis is run based on the patient's response:

Table 1. Sample of the analysis in light of the patient's response (1)

\begin{tabular}{|l|l|l|}
\hline Item & Score & Explanation for score \\
\hline Mary and Buurs & 0 & $\begin{array}{l}\text { "Mary and" are correct; } \\
\text { "Byron" is omitted; "Branes" } \\
\text { is misspelled and illegible. }\end{array}$ \\
\hline 2912 Honeycreek Rd & 1 & $\begin{array}{l}\text { Accurate, correctly spelled, } \\
\text { legible. }\end{array}$ \\
\hline Chicago & 1 & Accurate, correctly spelled, \\
\hline
\end{tabular}




\begin{tabular}{|l|l|l|}
\hline & & legible. \\
\hline Illonis & 0 & Misspelled \\
\hline 62654 & 0 & Inaccurate \\
\hline
\end{tabular}

Table 2. Sample of the analysis in light of the patient's response (2)

\begin{tabular}{|l|l|l|}
\hline Item & Score & Explanation for score \\
\hline Mary and Byron Brnes & 0 & $\begin{array}{l}\text { "Mary and" are correct; the } \\
\text { "a" in "Branes" is illegible. } \\
\text { "2912" is correct; } \\
\text { "Honeycreek RD" is } \\
\text { illegible. }\end{array}$ \\
\hline Chicago & 0 & $\begin{array}{l}\text { Accurate, correctly spelled, } \\
\text { legible. }\end{array}$ \\
\hline elle & 1 & $\begin{array}{l}\text { The "I" in "Illionois" is } \\
\text { illegible; the abbreviation } \\
\text { instead of the whole word is } \\
\text { in accurate. }\end{array}$ \\
\hline 616 & 0 & \begin{tabular}{l} 
Illegible \\
\hline
\end{tabular} \\
\hline
\end{tabular}

Table 3. Sample of the analysis in light of the patient's response (3)

\begin{tabular}{|l|l|l|}
\hline Item & Score & Explanation for score \\
\hline Mary and Byran Burne & 0 & $\begin{array}{l}\text { "Mary and" are correct; the } \\
\text { "o" in "Byron" is illegible; } \\
\text { "Branes" is misspelled. }\end{array}$ \\
\hline 2912 Honey creek Drive & 0 & $\begin{array}{l}\text { "2912" is correct; } \\
\text { "Honeycreek" is inaccurate } \\
\text { because it is divided into two } \\
\text { words; "Drive" instead of } \\
\text { "RD" is inaccurate. }\end{array}$ \\
\hline Chcg & 0 & $\begin{array}{l}\text { The "i" is not dotted; the "a" } \\
\text { and the "o" are illegible; no } \\
\text { comma after the word } \\
\text { "Chicago" is inaccurate. }\end{array}$ \\
\hline Iilnois & 0 & Misspelled \\
\hline 600 & 0 & Illegible, inaccurate \\
\hline
\end{tabular}


Table 4. Sample of the analysis in light of the patient's response (4)

\begin{tabular}{|l|l|l|}
\hline Item & Score & Explanation for score \\
\hline Mary \& Byron Barnes & 0 & $\begin{array}{l}\text { "\&" substituted for "and" is } \\
\text { inaccurate. }\end{array}$ \\
\hline 2912 Honeycreek Rd & 1 & $\begin{array}{l}\text { Accurate, correctly spelled, } \\
\text { legible. }\end{array}$ \\
\hline Chicago & 1 & $\begin{array}{l}\text { Accurate, correctly spelled, } \\
\text { legible. }\end{array}$ \\
\hline Illois & 0 & Misspelled \\
\hline 60026 & 0 & Inaccurate \\
\hline
\end{tabular}

Table 5. Sample of the analysis in light of the patient's response (5)

\begin{tabular}{|l|l|l|}
\hline Item & Score & Explanation for score \\
\hline Mary and Byron Barna & 0 & $\begin{array}{l}\text { "Mary and" are correct; the } \\
\text { "rn" in "Barnes" is illegible, } \\
\text { "e" looks like "a" (there is no } \\
\text { scoring penalty for the } \\
\text { writing slant toward the } \\
\text { upper right corner) }\end{array}$ \\
\hline 2912 Honeyweek Road & 0 & $\begin{array}{l}\text { "2912: is correct; } \\
\text { "Honeycreek" is misspelled } \\
\text { and illegible; "Road" instead } \\
\text { of "Rd." is inaccurate. }\end{array}$ \\
\hline Checago & 0 & $\begin{array}{l}\text { Inaccurate. } \\
\text { Illegible, the second "I" looks } \\
\text { like "e"; "o" looks like an } \\
\text { "a". }\end{array}$ \\
\hline 606226 & 0 & The extra 2 is inaccurate. \\
\hline
\end{tabular}

These above mentioned question samples indicate that questions were made in a way that makes evaluation process very simple. Such evaluations, in turn, make the test valid.

\subsection{Reliability of ALFA (Arabic version)}

The reliability of a test is known to make it acceptable and trusted by SLP/Ts, psychoneurolinguists and other people in the field, but little is known as to whether or not unremarkable significant differences affect the reliability of the test. Methodologically speaking, the test is valid when the results do not significantly change if we administer it under the same or at least similar conditions. In others, it gives the same outcome every time we use it. In order to dis/prove such characteristic, the researcher administered pre-and-posttest. 


\subsubsection{Pre-test}

As it is mentioned in the methodology of this study, the participating subjects were 50 male aphasics comparable to 50 female aphasics who underwent ALFA test in the first day of the first week. Fear conditioning and extinction anxiety occurred in the time before the test. However, the testers made it clear to the subjects in question that the test is easy and that they (participating subjects) have to relax. Table 6 illustrates the performance of the subjects under investigation. Consider:

Table 6. Participants' scores in ALFA pre-test

\begin{tabular}{|c|c|c|c|c|c|c|c|c|c|c|c|c|c|}
\hline 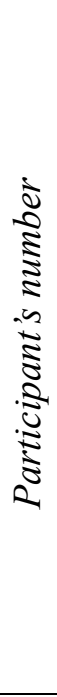 & 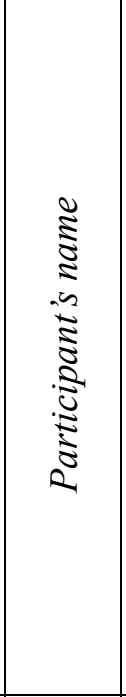 & 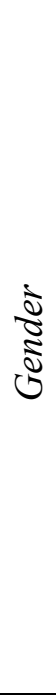 & 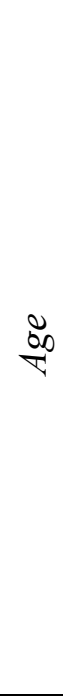 & 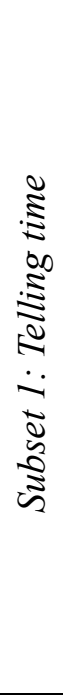 & 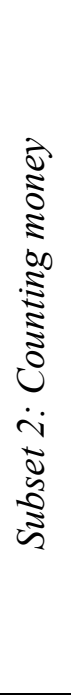 & 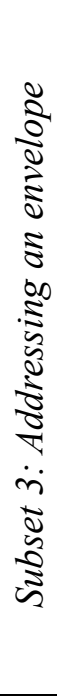 & 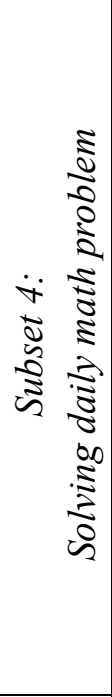 & 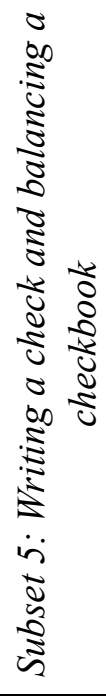 & 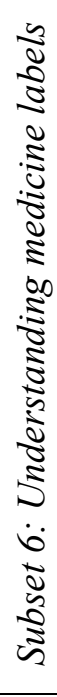 & 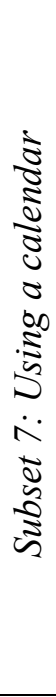 & 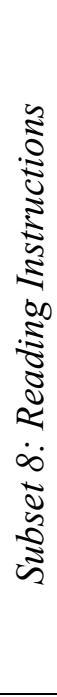 & 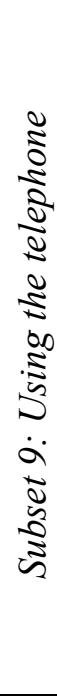 & 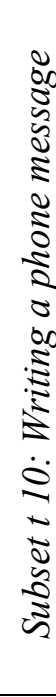 \\
\hline 1 & Y A U & $\mathrm{M}$ & 64 & 9 & 5 & 6 & 5 & 3 & 4 & 7 & 6 & 5 & 11 \\
\hline 2 & A Y K & $\mathrm{M}$ & 59 & 5 & 3 & 1 & 6 & 5 & 4 & 7 & 5 & 1 & 12 \\
\hline 3 & S A Y & $\mathrm{F}$ & 37 & 4 & 4 & 9 & 7 & 2 & 5 & 3 & 6 & 8 & 9 \\
\hline 4 & S S A & $\mathrm{M}$ & 61 & 10 & 7 & 8 & 8 & 9 & 8 & 2 & 7 & 0 & 13 \\
\hline 5 & S I F & $\mathrm{F}$ & 60 & 9 & 9 & 7 & 4 & 3 & 9 & 8 & 3 & 9 & 10 \\
\hline 6 & S B K & $\mathrm{F}$ & 28 & 8 & 8 & 5 & 9 & 7 & 3 & 9 & 7 & 5 & 8 \\
\hline 7 & M S U & $\mathrm{F}$ & 37 & 6 & 5 & 4 & 7 & 5 & 4 & 2 & 8 & 4 & 6 \\
\hline 8 & M O D & M & 32 & 7 & 4 & 2 & 8 & 4 & 6 & 1 & 9 & 3 & 8 \\
\hline 9 & S M A & $\mathrm{F}$ & 61 & 2 & 7 & 5 & 10 & 9 & 8 & 5 & 4 & 6 & 9 \\
\hline 10 & F S C & $\mathrm{F}$ & 64 & 3 & 6 & 9 & 10 & 8 & 9 & 6 & 5 & 7 & 12 \\
\hline 11 & $\mathrm{ASO}$ & $\mathrm{M}$ & 59 & 7 & 1 & 8 & 8 & 3 & 6 & 9 & 7 & 2 & 11 \\
\hline 12 & Y M H & $\mathrm{F}$ & 52 & 5 & 2 & 7 & 9 & 10 & 10 & 7 & 9 & 1 & 10 \\
\hline 13 & $\mathrm{~A} \mathrm{~J} \mathrm{~A}$ & $\mathrm{M}$ & 29 & 4 & 8 & 9 & 4 & 9 & 3 & 8 & 2 & 7 & 10 \\
\hline 14 & A G I & $\mathrm{M}$ & 25 & 10 & 9 & 8 & 5 & 8 & 4 & 0 & 3 & 8 & 11 \\
\hline 15 & A S E & M & 39 & 9 & 6 & 5 & 7 & 6 & 7 & 9 & 8 & 9 & 11 \\
\hline 16 & A A S & $\mathrm{F}$ & 63 & 9 & 4 & 4 & 8 & 3 & 9 & 2 & 9 & 7 & 13 \\
\hline 17 & H A W & $\mathrm{F}$ & 68 & 8 & 3 & 3 & 2 & 2 & 5 & 9 & 6 & 5 & 14 \\
\hline 18 & F A S & M & 17 & 6 & 7 & 9 & 3 & 9 & 6 & 5 & 5 & 4 & 14 \\
\hline
\end{tabular}




\section{$\triangle M_{\text {Institute }}^{\text {Macrothink }}$}

\begin{tabular}{|c|c|c|c|c|c|c|c|c|c|c|c|c|c|}
\hline 19 & H A A & $\mathrm{F}$ & 62 & 6 & 8 & 8 & 8 & 5 & 7 & 4 & 4 & 3 & 15 \\
\hline 20 & M A C & $\mathrm{M}$ & 29 & 6 & 9 & 4 & 9 & 4 & 8 & 5 & 7 & 7 & 10 \\
\hline 21 & $\mathrm{O}$ M C & $\mathrm{M}$ & 17 & 8 & 3 & 5 & 7 & 9 & 3 & 3 & 8 & 8 & 9 \\
\hline 22 & A S O & $F$ & 54 & 7 & 4 & 8 & 4 & 8 & 4 & 6 & 9 & 2 & 11 \\
\hline 23 & H S N & $\mathrm{M}$ & 56 & 9 & 8 & 7 & 5 & 2 & 8 & 3 & 2 & 0 & 13 \\
\hline 24 & A B H & $\mathrm{M}$ & 61 & 9 & 7 & 3 & 9 & 3 & 9 & 7 & 3 & 2 & 14 \\
\hline 25 & S H U & $\mathrm{F}$ & 64 & 10 & 6 & 4 & 10 & 9 & 9 & 3 & 4 & 9 & 14 \\
\hline 26 & M A N & $\mathrm{F}$ & 19 & 8 & 5 & 5 & 6 & 0 & 5 & 2 & 5 & 1 & 14 \\
\hline 27 & S B D & M & 47 & 9 & 8 & 9 & 7 & 1 & 6 & 9 & 9 & 8 & 13 \\
\hline 28 & A B R & $\mathrm{F}$ & 60 & 6 & 9 & 0 & 3 & 6 & 6 & 0 & 8 & 9 & 15 \\
\hline 29 & A B E & $\mathrm{M}$ & 45 & 5 & 10 & 2 & 4 & 8 & 5 & 2 & 9 & 9 & 11 \\
\hline 30 & N S D & $\mathrm{F}$ & 46 & 4 & 7 & 1 & 8 & 7 & 5 & 1 & 7 & 8 & 12 \\
\hline 31 & A S S & $\mathrm{M}$ & 43 & 7 & 6 & 4 & 9 & 9 & 5 & 7 & 7 & 2 & 10 \\
\hline 32 & N S P & $F$ & 53 & 6 & 5 & 3 & 5 & 9 & 5 & 9 & 6 & 1 & 10 \\
\hline 33 & A S S & $\mathrm{M}$ & 25 & 9 & 8 & 10 & 4 & 10 & 2 & 8 & 6 & 7 & 9 \\
\hline 34 & A M S & $F$ & 47 & 10 & 9 & 8 & 7 & 7 & 3 & 0 & 8 & 8 & 12 \\
\hline 35 & M A S & $\mathrm{M}$ & 31 & 5 & 10 & 6 & 8 & 4 & 7 & 9 & 9 & 4 & 12 \\
\hline 36 & A L & $\mathrm{M}$ & 48 & 6 & 10 & 9 & 9 & 5 & 8 & 7 & 4 & 3 & 14 \\
\hline 37 & A A S & $\mathrm{M}$ & 29 & 8 & 10 & 6 & 5 & 9 & 9 & 5 & 3 & 7 & 15 \\
\hline 38 & A M A & $\mathrm{M}$ & 53 & 9 & 10 & 4 & 6 & 8 & 10 & 3 & 5 & 5 & 12 \\
\hline 39 & K A & M & 27 & 5 & 3 & 3 & 7 & 3 & 3 & 1 & 6 & 9 & 10 \\
\hline 40 & N A & $\mathrm{F}$ & 25 & 3 & 4 & 9 & 8 & 9 & 3 & 1 & 7 & 8 & 9 \\
\hline 41 & S A S & $\mathrm{M}$ & 55 & 1 & 7 & 8 & 3 & 7 & 5 & 4 & 8 & 2 & 12 \\
\hline 42 & S A D & M & 57 & 6 & 6 & 7 & 2 & 8 & 6 & 3 & 9 & 3 & 8 \\
\hline 43 & M B A & M & 29 & 7 & 5 & 5 & 4 & 4 & 7 & 9 & 2 & 6 & 10 \\
\hline 44 & A K A & $\mathrm{F}$ & 49 & 8 & 8 & 6 & 6 & 3 & 8 & 8 & 2 & 5 & 11 \\
\hline 45 & A L A & $\mathrm{F}$ & 24 & 9 & 7 & 3 & 8 & 5 & 2 & 10 & 10 & 4 & 15 \\
\hline 46 & S U & $\mathrm{M}$ & 48 & 5 & 9 & 2 & 9 & 6 & 9 & 10 & 2 & 9 & 15 \\
\hline 47 & AA L & $\mathrm{M}$ & 50 & 4 & 5 & 8 & 5 & 7 & 0 & 0 & 8 & 8 & 9 \\
\hline 48 & A Y A & $\mathrm{F}$ & 26 & 9 & 4 & 9 & 4 & 8 & 1 & 8 & 9 & 7 & 11 \\
\hline 49 & A M A & $\mathrm{F}$ & 52 & 8 & 2 & 5 & 10 & 10 & 4 & 9 & 10 & 5 & 13 \\
\hline 50 & A A A & $\mathrm{F}$ & 54 & 5 & 7 & 3 & 10 & 8 & 6 & 8 & 3 & 9 & 12 \\
\hline 51 & A M J & $\mathrm{F}$ & 20 & 4 & 8 & 7 & 9 & 7 & 9 & 7 & 4 & 2 & 10 \\
\hline 52 & R G A & $\mathrm{F}$ & 63 & 8 & 9 & 6 & 9 & 1 & 3 & 6 & 7 & 7 & 8 \\
\hline 53 & A R & $F$ & 64 & 9 & 5 & 3 & 3 & 2 & 4 & 5 & 8 & 8 & 12 \\
\hline 54 & $\mathrm{H} \mathrm{M}$ & $F$ & 21 & 10 & 6 & 9 & 4 & 0 & 8 & 9 & 9 & 9 & 9 \\
\hline 55 & B D A & $\mathrm{M}$ & 20 & 9 & 4 & 8 & 5 & 9 & 9 & 7 & 10 & 9 & 11 \\
\hline 56 & P A & $\mathrm{M}$ & 64 & 5 & 3 & 10 & 2 & 8 & 5 & 4 & 9 & 9 & 15 \\
\hline 57 & B R & $\mathrm{M}$ & 17 & 8 & 2 & 10 & 4 & 2 & 4 & 3 & 8 & 1 & 12 \\
\hline
\end{tabular}




\section{MInstitute Macrothink $^{\text {Int }}$}

\begin{tabular}{|c|c|c|c|c|c|c|c|c|c|c|c|c|c|}
\hline 58 & B R A & $\mathrm{F}$ & 49 & 7 & 5 & 10 & 5 & 3 & 8 & 8 & 1 & 5 & 8 \\
\hline 59 & T R Q & F & 59 & 3 & 6 & 9 & 8 & 4 & 9 & 7 & 6 & 8 & 13 \\
\hline 60 & T M H & $\mathrm{M}$ & 31 & 9 & 7 & 8 & 9 & 6 & 10 & 4 & 7 & 6 & 9 \\
\hline 61 & T H A & M & 16 & 7 & 8 & 6 & 9 & 7 & 9 & 5 & 8 & 6 & 14 \\
\hline 62 & H D A & M & 65 & 8 & 0 & 5 & 5 & 9 & 8 & 0 & 9 & 2 & 10 \\
\hline 63 & SA S & $F$ & 49 & 9 & 2 & 4 & 6 & 8 & 6 & 9 & 10 & 1 & 11 \\
\hline 64 & A D K & $\mathrm{F}$ & 19 & 10 & 3 & 3 & 4 & 8 & 3 & 0 & 10 & 2 & 12 \\
\hline 65 & S D Q & $\mathrm{F}$ & 48 & 8 & 4 & 1 & 7 & 7 & 4 & 10 & 10 & 5 & 11 \\
\hline 66 & H N A & $\mathrm{F}$ & 45 & 9 & 5 & 9 & 8 & 6 & 6 & 1 & 2 & 5 & 15 \\
\hline 67 & K M L & $\mathrm{F}$ & 34 & 5 & 6 & 8 & 3 & 2 & 8 & 4 & 4 & 6 & 12 \\
\hline 68 & H J R & $\mathrm{F}$ & 61 & 4 & 7 & 7 & 2 & 3 & 9 & 5 & 6 & 9 & 9 \\
\hline 69 & H M S & $\mathrm{F}$ & 65 & 8 & 9 & 5 & 4 & 4 & 3 & 7 & 9 & 9 & 8 \\
\hline 70 & R S D & $\mathrm{F}$ & 29 & 6 & 2 & 4 & 6 & 5 & 4 & 8 & 7 & 0 & 12 \\
\hline 71 & $\mathrm{O} \mathrm{M}$ & M & 17 & 9 & 3 & 2 & 8 & 9 & 5 & 2 & 5 & 0 & 7 \\
\hline 72 & A S R & M & 64 & 8 & 8 & 9 & 9 & 8 & 6 & 9 & 6 & 1 & 11 \\
\hline 73 & A L I & $\mathrm{F}$ & 54 & 5 & 6 & 8 & 10 & 6 & 2 & 8 & 10 & 6 & 13 \\
\hline 74 & M H D & M & 33 & 4 & 5 & 7 & 4 & 3 & 1 & 7 & 5 & 3 & 14 \\
\hline 75 & M T H & M & 55 & 1 & 3 & 4 & 5 & 2 & 2 & 4 & 6 & 9 & 14 \\
\hline 76 & A Y M & $\mathrm{M}$ & 49 & 9 & 7 & 9 & 8 & 10 & 4 & 5 & 8 & 7 & 14 \\
\hline 77 & A D H & M & 47 & 8 & 8 & 8 & 9 & 9 & 6 & 9 & 9 & 6 & 14 \\
\hline 78 & A Y H & $\mathrm{F}$ & 64 & 10 & 2 & 6 & 5 & 7 & 8 & 8 & 3 & 7 & 8 \\
\hline 79 & N R & M & 30 & 1 & 2 & 7 & 4 & 5 & 9 & 7 & 4 & 7 & 9 \\
\hline 80 & N J B & $\mathrm{M}$ & 22 & 9 & 5 & 9 & 7 & 3 & 5 & 1 & 5 & 7 & 9 \\
\hline 81 & T F Q & $\mathrm{M}$ & 20 & 9 & 8 & 8 & 8 & 2 & 6 & 7 & 9 & 1 & 15 \\
\hline 82 & R D A & $\mathrm{F}$ & 62 & 5 & 9 & 7 & 9 & 9 & 7 & 3 & 10 & 4 & 8 \\
\hline 83 & W F A & $\mathrm{F}$ & 38 & 4 & 9 & 4 & 10 & 7 & 8 & 4 & 10 & 4 & 8 \\
\hline 84 & W J D & $\mathrm{M}$ & 25 & 8 & 2 & 2 & 10 & 6 & 3 & 8 & 10 & 1 & 8 \\
\hline 85 & H N A & $\mathrm{F}$ & 19 & 7 & 3 & 4 & 10 & 5 & 4 & 9 & 9 & 8 & 9 \\
\hline 86 & S N S & $\mathrm{F}$ & 59 & 6 & 6 & 5 & 6 & 3 & 2 & 4 & 9 & 8 & 12 \\
\hline 87 & A S N & $\mathrm{F}$ & 44 & 9 & 6 & 6 & 7 & 4 & 3 & 8 & 9 & 1 & 15 \\
\hline 88 & A N S & $\mathrm{M}$ & 61 & 8 & 7 & 8 & 8 & 9 & 8 & 7 & 7 & 1 & 14 \\
\hline 89 & O M R & $\mathrm{M}$ & 65 & 9 & 7 & 7 & 8 & 8 & 9 & 5 & 5 & 7 & 12 \\
\hline 90 & A M J & $\mathrm{F}$ & 63 & 10 & 7 & 9 & 9 & 6 & 7 & 10 & 3 & 6 & 9 \\
\hline 91 & H S N & $\mathrm{M}$ & 17 & 9 & 8 & 9 & 9 & 10 & 6 & 9 & 4 & 3 & 10 \\
\hline 92 & A B J & $\mathrm{M}$ & 21 & 7 & 9 & 8 & 9 & 9 & 3 & 4 & 8 & 2 & 10 \\
\hline 93 & K L D & $\mathrm{F}$ & 18 & 5 & 9 & 5 & 9 & 8 & 2 & 3 & 9 & 9 & 12 \\
\hline 94 & S T N & $\mathrm{F}$ & 56 & 2 & 8 & 4 & 1 & 3 & 1 & 8 & 2 & 8 & 14 \\
\hline 95 & R H M & $\mathrm{F}$ & 23 & 10 & 5 & 3 & 3 & 4 & 0 & 7 & 3 & 7 & 15 \\
\hline 96 & A B L & $\mathrm{M}$ & 34 & 9 & 6 & 8 & 5 & 9 & 5 & 6 & 8 & 6 & 9 \\
\hline
\end{tabular}




\begin{tabular}{|c|c|c|c|c|c|c|c|c|c|c|c|}
\hline 97 T M A & M & 17 & 8 & 5 & 7 & 6 & 6 & 7 & 9 & 1 & 12 \\
\hline \begin{tabular}{l|l|}
98 & N Q S \\
\end{tabular} & $\mathrm{F}$ & 60 & 7 & 5 & 6 & 7 & 7 & 6 & 10 & 2 & 13 \\
\hline 99 N M Z & $\mathrm{F}$ & 45 & 6 & 6 & 5 & 6 & 8 & 5 & 2 & 4 & 15 \\
\hline $100 \mid \mathrm{N} \mathrm{M} \mathrm{H}$ & $\mathrm{M}$ & 55 & 5 & 6 & 9 & 7 & 3 & 6 & 5 & 3 & 15 \\
\hline \multicolumn{7}{|c|}{ Total number of participants } & \multicolumn{5}{|c|}{100 (50 males and 50 females) } \\
\hline \multicolumn{7}{|c|}{ Mean of ages } & \multicolumn{5}{|c|}{43.94} \\
\hline \multicolumn{7}{|c|}{ Total of scores } & \multicolumn{5}{|c|}{6993} \\
\hline \multicolumn{7}{|c|}{ Mean and level of telling time's scores } & \multicolumn{5}{|c|}{6.9 (Level 2) } \\
\hline \multicolumn{7}{|c|}{ Mean and level of counting money's scores } & \multicolumn{5}{|c|}{6.98 (Level 2) } \\
\hline \multicolumn{7}{|c|}{ Mean and level of addressing an envelope's scores } & \multicolumn{5}{|c|}{6.03 (Level 2) } \\
\hline \multicolumn{7}{|c|}{ Mean and level of solving daily math problems' scores } & \multicolumn{5}{|c|}{5.66 (Level 2) } \\
\hline \multicolumn{7}{|c|}{$\begin{array}{l}\text { Mean and level of writing a check and balancing } \\
\text { a checkbook's scores }\end{array}$} & \multicolumn{5}{|c|}{5.97 (Level 2) } \\
\hline \multicolumn{7}{|c|}{ Mean and level of understanding medicine labels' scores } & \multicolumn{5}{|c|}{5.62 (Level 2) } \\
\hline \multicolumn{7}{|c|}{ Mean and level of using a calendar's scores } & \multicolumn{5}{|c|}{5.64 (Level 2) } \\
\hline \multicolumn{7}{|c|}{ Mean and level of reading instructions' scores } & \multicolumn{5}{|c|}{6.54 (Level 2) } \\
\hline \multicolumn{7}{|c|}{ Mean and level of using the telephone's scores } & \multicolumn{5}{|c|}{5.12 (Level 3) } \\
\hline \multicolumn{7}{|c|}{ Mean and level of writing a phone message's scores } & \multicolumn{5}{|c|}{10.95 (Level 3) } \\
\hline \multicolumn{7}{|c|}{ General mean of number correct } & \multicolumn{5}{|c|}{6.541} \\
\hline \multicolumn{7}{|c|}{ General mean of independent functioning rating (levels) } & \multicolumn{5}{|c|}{2.1} \\
\hline \multicolumn{7}{|c|}{ Hypothetical mean } & \multicolumn{5}{|c|}{699.3} \\
\hline
\end{tabular}

The results obtained from the analysis of the aphasics' performance are scores known to be qualitatively and statistically reliable. We used the record of scores and the independent functioning ratings to determine in which level the performance of the aphasics under investigation falls. Table 6 reveals some of the results where nearly most results fall into the second level. With the exception of scores of the category entitles: "writing a phone message." which overpass the standard followed by other categories due to statistical considerations, other scores registered the same level (2) except for those related to using the telephone category which fell in the third level. In details, subsets can be divided into two groups: Group one consist of scores below 6. Under this group, one can clearly find subsets of solving daily math problems, writing a check and balancing a checkbook, understanding medicine labels, using a calendar, and using the telephone. Note here that the subset entitled: "using the telephone", falls into this group although it belongs to level three (3).

On the other hand, group 2 contains all those scores above 6 . This includes the following subsets: Telling time, counting money, addressing an envelope, and reading instructions. Generally, scores relating to the first group are more than those of the second one. Regardless the differences between the scores themselves, it can be said that both group are close it each other which means that the differences are not significant or remarkable. It is for this reason, however, that they nearly belong to the same level and also the same mean (2 and 2.1, respectively). Likewise, general mean of number correct scores and hypothetical mean nearly 
fall into the same category (6). Strictly, these findings will be clearer in light of the participant's performance in the posttest.

\subsubsection{Posttest}

This is one of the first ALFA studies in the Arab world to test the validity and reliability of this test between Arab aphasics with different types of language impairments. The results of the pre-test may suggest another test to confirm them. It is for this reason, however, that the researchers administer posttest. As it is mentioned somewhere throughout the research, the posttest was administered at the end of the third week of this experimental study. Table 7 summarizes the performance of the participating subjects. Consider:

Table 7. ALFA posttest: Performance of aphasic participants

\begin{tabular}{|c|c|c|c|c|c|c|c|c|c|c|c|c|c|}
\hline 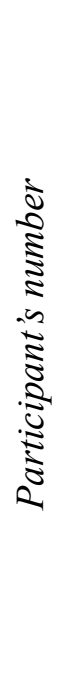 & 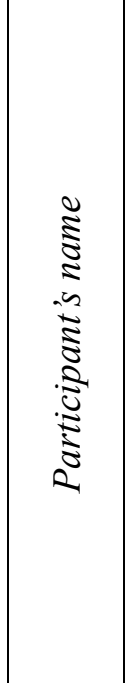 & 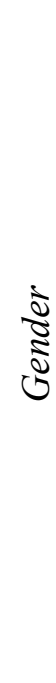 & $\underset{\infty}{\infty}$ & 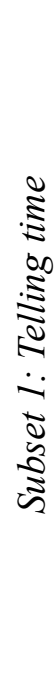 & 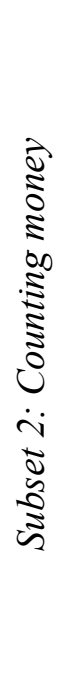 & 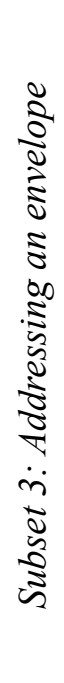 & 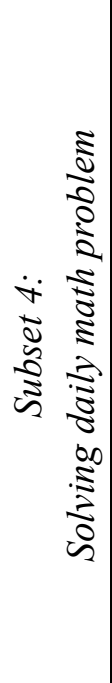 & 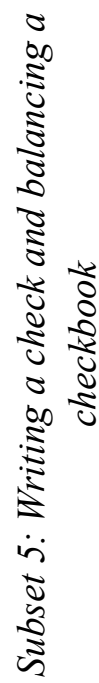 & 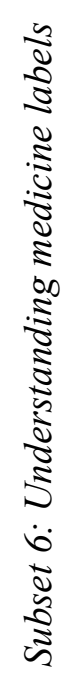 & 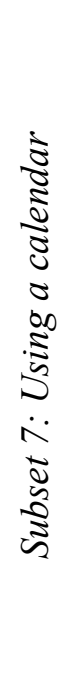 & 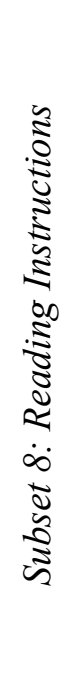 & 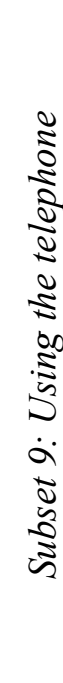 & 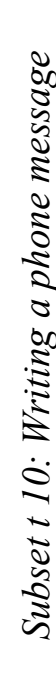 \\
\hline 1 & Y A U & $\mathrm{M}$ & 64 & 1 & 6 & 5 & 3 & 8 & 8 & 9 & 9 & 7 & 14 \\
\hline 2 & A Y K & M & 59 & 2 & 1 & 1 & 2 & 9 & 5 & 9 & 8 & 8 & 15 \\
\hline 3 & S A Y & $\mathrm{F}$ & 37 & 1 & 1 & 9 & 2 & 9 & 9 & 9 & 9 & 10 & 13 \\
\hline 4 & S S A & M & 61 & 2 & 0 & 4 & 2 & 7 & 8 & 8 & 9 & 9 & 14 \\
\hline 5 & S I F & $\mathrm{F}$ & 60 & 1 & 1 & 3 & 3 & 8 & 9 & 9 & 8 & 10 & 15 \\
\hline 6 & S B K & $\mathrm{F}$ & 28 & 9 & 0 & 3 & 2 & 9 & 8 & 8 & 9 & 9 & 12 \\
\hline 7 & M S U & $\mathrm{F}$ & 37 & 2 & 2 & 4 & 2 & 8 & 8 & 8 & 10 & 9 & 13 \\
\hline 8 & M O D & M & 32 & 2 & 2 & 2 & 3 & 9 & 6 & 9 & 9 & 10 & 15 \\
\hline 9 & S M A & $\mathrm{F}$ & 61 & 1 & 1 & 2 & 1 & 8 & 7 & 10 & 9 & 9 & 13 \\
\hline 10 & F S C & $\mathrm{F}$ & 64 & 2 & 0 & 3 & 1 & 9 & 9 & 10 & 8 & 9 & 14 \\
\hline 11 & A S O & M & 59 & 1 & 0 & 8 & 2 & 8 & 6 & 10 & 6 & 10 & 13 \\
\hline 12 & Y M H & $\mathrm{F}$ & 52 & 9 & 1 & 3 & 4 & 9 & 10 & 9 & 9 & 10 & 14 \\
\hline 13 & $\mathrm{~A} \mathrm{~J} \mathrm{~A}$ & M & 29 & 9 & 0 & 2 & 1 & 8 & 10 & 9 & 7 & 9 & 14 \\
\hline 14 & A G I & M & 25 & 8 & 3 & 2 & 1 & 9 & 10 & 10 & 9 & 10 & 14 \\
\hline 15 & A S E & M & 39 & 2 & 2 & 1 & 2 & 9 & 8 & 10 & 7 & 10 & 13 \\
\hline 16 & AAS & $\mathrm{F}$ & 63 & 9 & 2 & 1 & 2 & 9 & 9 & 9 & 10 & 9 & 13 \\
\hline 17 & H A W & $\mathrm{F}$ & 68 & 9 & 2 & 2 & 2 & 9 & 9 & 10 & 9 & 9 & 14 \\
\hline
\end{tabular}




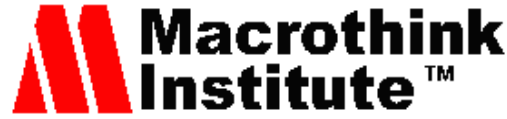

\begin{tabular}{|c|c|c|c|c|c|c|c|c|c|c|c|c|c|}
\hline 18 & F A S & $\mathrm{M}$ & 17 & 9 & 1 & 2 & 2 & 9 & 10 & 9 & 7 & 9 & 15 \\
\hline 19 & H A A & $\mathrm{F}$ & 62 & 3 & 2 & 1 & 2 & 8 & 10 & 9 & 6 & 10 & 13 \\
\hline 20 & M A C & $\mathrm{M}$ & 29 & 9 & 0 & 2 & 3 & 8 & 9 & 10 & 9 & 10 & 15 \\
\hline 21 & $\mathrm{O} \mathrm{M} \mathrm{C}$ & $\mathrm{M}$ & 17 & 10 & 1 & 2 & 2 & 8 & 7 & 10 & 8 & 9 & 13 \\
\hline 22 & A S O & $\mathrm{F}$ & 54 & 0 & 2 & 2 & 1 & 9 & 8 & 10 & 8 & 9 & 15 \\
\hline 23 & H S N & M & 56 & 9 & 9 & 2 & 3 & 9 & 9 & 9 & 8 & 10 & 14 \\
\hline 24 & A B H & M & 61 & 8 & 1 & 2 & 9 & 9 & 9 & 9 & 8 & 9 & 15 \\
\hline 25 & $\mathrm{~S}$ H U & $\mathrm{F}$ & 64 & 1 & 0 & 2 & 10 & 9 & 8 & 9 & 8 & 10 & 15 \\
\hline 26 & M A N & $\mathrm{F}$ & 19 & 6 & 1 & 3 & 3 & 10 & 8 & 8 & 6 & 9 & 15 \\
\hline 27 & S B D & $\mathrm{M}$ & 47 & 8 & 0 & 2 & 2 & 10 & 8 & 8 & 10 & 9 & 15 \\
\hline 28 & A B R & $\mathrm{F}$ & 60 & 9 & 1 & 0 & 3 & 10 & 8 & 10 & 9 & 10 & 15 \\
\hline 29 & A B E & $\mathrm{M}$ & 45 & 0 & 1 & 4 & 1 & 10 & 10 & 9 & 9 & 10 & 14 \\
\hline 30 & N S D & $\mathrm{F}$ & 46 & 0 & 3 & 1 & 2 & 10 & 9 & 10 & 8 & 9 & 14 \\
\hline 31 & A S S & M & 43 & 0 & 2 & 3 & 3 & 8 & 8 & 9 & 9 & 9 & 13 \\
\hline 32 & N S P & $\mathrm{F}$ & 53 & 0 & 4 & 2 & 3 & 9 & 9 & 10 & 6 & 10 & 14 \\
\hline 33 & A S S & $\mathrm{M}$ & 25 & 6 & 3 & 1 & 5 & 10 & 8 & 9 & 7 & 9 & 15 \\
\hline 34 & A M S & $\mathrm{F}$ & 47 & 9 & 3 & 2 & 4 & 9 & 9 & 10 & 8 & 9 & 15 \\
\hline 35 & M A S & $\mathrm{M}$ & 31 & 1 & 2 & 0 & 3 & 9 & 9 & 10 & 9 & 9 & 14 \\
\hline 36 & A L & $\mathrm{M}$ & 48 & 1 & 7 & 0 & 3 & 9 & 9 & 8 & 8 & 9 & 15 \\
\hline 37 & A A S & $\mathrm{M}$ & 29 & 1 & 1 & 0 & 3 & 9 & 10 & 9 & 8 & 9 & 15 \\
\hline 38 & A M A & $\mathrm{M}$ & 53 & 7 & 10 & 0 & 2 & 8 & 9 & 10 & 8 & 10 & 15 \\
\hline 39 & K A & M & 27 & 2 & 2 & 0 & 3 & 7 & 9 & 10 & 8 & 9 & 14 \\
\hline 40 & N A & $\mathrm{F}$ & 25 & 1 & 1 & 9 & 0 & 9 & 10 & 10 & 9 & 9 & 14 \\
\hline 41 & S A S & $\mathrm{M}$ & 55 & 9 & 0 & 5 & 2 & 7 & 9 & 8 & 9 & 10 & 14 \\
\hline 42 & S A D & $\mathrm{M}$ & 57 & 9 & 2 & 6 & 2 & 8 & 9 & 7 & 9 & 7 & 15 \\
\hline 43 & M B A & $\mathrm{M}$ & 29 & 9 & 3 & 7 & 4 & 8 & 10 & 10 & 9 & 9 & 14 \\
\hline 44 & A K A & $\mathrm{F}$ & 49 & 1 & 1 & 5 & 3 & 7 & 9 & 9 & 8 & 9 & 15 \\
\hline 45 & A L A & $\mathrm{F}$ & 24 & 2 & 1 & 5 & 4 & 6 & 9 & 10 & 10 & 9 & 14 \\
\hline 46 & S U & $\mathrm{M}$ & 48 & 9 & 2 & 4 & 4 & 6 & 10 & 10 & 9 & 10 & 15 \\
\hline 47 & A A L & $\mathrm{M}$ & 50 & 2 & 2 & 3 & 4 & 7 & 9 & 9 & 9 & 9 & 14 \\
\hline 48 & A Y A & $\mathrm{F}$ & 26 & 1 & 2 & 3 & 6 & 9 & 9 & 9 & 9 & 9 & 14 \\
\hline 49 & A M A & $\mathrm{F}$ & 52 & 3 & 0 & 3 & 1 & 9 & 10 & 8 & 10 & 9 & 14 \\
\hline 50 & A A A & $\mathrm{F}$ & 54 & 2 & 0 & 5 & 1 & 6 & 9 & 9 & 9 & 10 & 15 \\
\hline 51 & A M J & $\mathrm{F}$ & 20 & 1 & 0 & 5 & 2 & 7 & 10 & 7 & 9 & 9 & 14 \\
\hline 52 & R G A & $\mathrm{F}$ & 63 & 2 & 0 & 6 & 1 & 6 & 9 & 8 & 8 & 9 & 15 \\
\hline 53 & A R & $\mathrm{F}$ & 64 & 9 & 1 & 6 & 1 & 6 & 9 & 8 & 9 & 10 & 14 \\
\hline 54 & $\mathrm{H} \mathrm{M}$ & $\mathrm{F}$ & 21 & 1 & 2 & 5 & 1 & 6 & 9 & 8 & 9 & 10 & 15 \\
\hline 55 & B D A & $\mathrm{M}$ & 20 & 1 & 2 & 4 & 5 & 8 & 10 & 8 & 10 & 10 & 14 \\
\hline 56 & P A & $\mathrm{M}$ & 64 & 2 & 3 & 1 & 1 & 8 & 7 & 9 & 9 & 9 & 15 \\
\hline
\end{tabular}




\section{MInstitute Macrothink $_{\text {Int }}^{\text {Int }}$}

\begin{tabular}{|c|c|c|c|c|c|c|c|c|c|c|c|c|c|}
\hline 57 & B R & $\mathrm{M}$ & 17 & 2 & 2 & 1 & 2 & 8 & 9 & 8 & 9 & 10 & 14 \\
\hline 58 & B R A & $\mathrm{F}$ & 49 & 1 & 3 & 8 & 3 & 9 & 7 & 9 & 9 & 10 & 14 \\
\hline 59 & T R Q & $\mathrm{F}$ & 59 & 2 & 2 & 8 & 3 & 6 & 8 & 9 & 10 & 10 & 15 \\
\hline 60 & T M H & $\mathrm{M}$ & 31 & 1 & 1 & 3 & 3 & 7 & 9 & 10 & 9 & 9 & 14 \\
\hline 61 & THA & $\mathrm{M}$ & 16 & 3 & 2 & 1 & 4 & 7 & 8 & 9 & 9 & 9 & 14 \\
\hline 62 & H D A & $\mathrm{M}$ & 65 & 5 & 1 & 0 & 5 & 6 & 7 & 9 & 9 & 9 & 15 \\
\hline 63 & SA S & $\mathrm{F}$ & 49 & 3 & 2 & 0 & 6 & 6 & 9 & 10 & 10 & 10 & 15 \\
\hline 64 & A D K & $\mathrm{F}$ & 19 & 1 & 2 & 0 & 4 & 6 & 8 & 9 & 10 & 10 & 14 \\
\hline 65 & S D Q & $\mathrm{F}$ & 48 & 3 & 3 & 0 & 4 & 7 & 7 & 9 & 10 & 8 & 15 \\
\hline 66 & H N A & $\mathrm{F}$ & 45 & 2 & 3 & 2 & 3 & 8 & 7 & 10 & 9 & 7 & 15 \\
\hline 67 & K M L & $\mathrm{F}$ & 34 & 1 & 5 & 1 & 3 & 8 & 9 & 9 & 7 & 8 & 14 \\
\hline 68 & H J R & $\mathrm{F}$ & 61 & 2 & 0 & 2 & 2 & 9 & 9 & 9 & 8 & 10 & 15 \\
\hline 69 & H M S & $\mathrm{F}$ & 65 & 3 & 1 & 5 & 3 & 8 & 8 & 10 & 9 & 9 & 15 \\
\hline 70 & R S D & $\mathrm{F}$ & 29 & 2 & 0 & 2 & 0 & 9 & 8 & 9 & 9 & 9 & 14 \\
\hline 71 & $\mathrm{OM}$ & $\mathrm{M}$ & 17 & 1 & 1 & 3 & 0 & 5 & 8 & 10 & 8 & 8 & 15 \\
\hline 72 & A S R & $\mathrm{M}$ & 64 & 2 & 1 & 2 & 0 & 8 & 10 & 10 & 9 & 9 & 14 \\
\hline 73 & A L I & $\mathrm{F}$ & 54 & 0 & 2 & 1 & 10 & 9 & 9 & 9 & 10 & 7 & 14 \\
\hline 74 & M H D & $\mathrm{M}$ & 33 & 0 & 2 & 3 & 0 & 6 & 9 & 9 & 8 & 9 & 15 \\
\hline 75 & M T H & $\mathrm{M}$ & 55 & 0 & 2 & 4 & 0 & 8 & 9 & 9 & 8 & 8 & 14 \\
\hline 76 & A Y M & $\mathrm{M}$ & 49 & 0 & 2 & 2 & 1 & 9 & 9 & 10 & 9 & 9 & 14 \\
\hline 77 & A D H & $\mathrm{M}$ & 47 & 0 & 2 & 4 & 2 & 9 & 9 & 10 & 10 & 7 & 15 \\
\hline 78 & A Y H & $\mathrm{F}$ & 64 & 1 & 3 & 2 & 3 & 7 & 9 & 9 & 8 & 10 & 12 \\
\hline 79 & $\mathrm{~N} \mathrm{R}$ & $\mathrm{M}$ & 30 & 0 & 4 & 3 & 3 & 9 & 9 & 6 & 8 & 10 & 15 \\
\hline 80 & N J B & $\mathrm{M}$ & 22 & 0 & 3 & 2 & 4 & 9 & 9 & 10 & 8 & 10 & 14 \\
\hline 81 & T F Q & $\mathrm{M}$ & 20 & 0 & 6 & 1 & 5 & 9 & 9 & 9 & 9 & 10 & 15 \\
\hline 82 & R D A & $\mathrm{F}$ & 62 & 0 & 5 & 2 & 7 & 9 & 9 & 9 & 10 & 9 & 13 \\
\hline 83 & W F A & $\mathrm{F}$ & 38 & 9 & 0 & 2 & 0 & 6 & 9 & 8 & 10 & 9 & 15 \\
\hline 84 & W J D & $\mathrm{M}$ & 25 & 9 & 1 & 2 & 1 & 6 & 10 & 9 & 10 & 10 & 13 \\
\hline 85 & H N A & $\mathrm{F}$ & 19 & 9 & 1 & 1 & 1 & 6 & 10 & 10 & 9 & 9 & 11 \\
\hline 86 & S N S & $\mathrm{F}$ & 59 & 9 & 3 & 1 & 7 & 6 & 10 & 9 & 10 & 9 & 15 \\
\hline 87 & A S N & $\mathrm{F}$ & 44 & 0 & 2 & 2 & 5 & 6 & 10 & 10 & 10 & 10 & 13 \\
\hline 88 & A N S & $\mathrm{M}$ & 61 & 0 & 1 & 3 & 6 & 8 & 10 & 9 & 10 & 10 & 14 \\
\hline 89 & O M R & $\mathrm{M}$ & 65 & 1 & 2 & 3 & 5 & 8 & 10 & 9 & 9 & 9 & 15 \\
\hline 90 & A M J & $\mathrm{F}$ & 63 & 1 & 3 & 4 & 3 & 10 & 9 & 9 & 9 & 9 & 15 \\
\hline 91 & H S N & $\mathrm{M}$ & 17 & 2 & 0 & 2 & 6 & 9 & 9 & 10 & 10 & 8 & 11 \\
\hline 92 & A B J & $\mathrm{M}$ & 21 & 2 & 0 & 2 & 5 & 9 & 7 & 9 & 9 & 9 & 14 \\
\hline 93 & K L D & $\mathrm{F}$ & 18 & 1 & 0 & 2 & 5 & 9 & 6 & 8 & 10 & 10 & 12 \\
\hline 94 & S T N & $\mathrm{F}$ & 56 & 2 & 9 & 2 & 6 & 9 & 9 & 9 & 9 & 9 & 15 \\
\hline 95 & R H M & $\mathrm{F}$ & 23 & 1 & 9 & 3 & 2 & 8 & 6 & 9 & 10 & 9 & 15 \\
\hline
\end{tabular}




\begin{tabular}{|c|c|c|c|c|c|c|c|c|c|c|c|c|c|}
\hline 96 & A B L & M & 34 & 2 & 3 & 2 & 5 & 8 & 9 & 8 & 9 & 9 & 13 \\
\hline 97 & T M A & M & 17 & 3 & 3 & 1 & 3 & 9 & 7 & 9 & 10 & 10 & 14 \\
\hline 98 & N Q S & $\mathrm{F}$ & 60 & 3 & 3 & 2 & 3 & 9 & 8 & 8 & 10 & 9 & 14 \\
\hline 991 & N M Z & $\mathrm{F}$ & 45 & 3 & 4 & 2 & 2 & 9 & 9 & 7 & 8 & 10 & 15 \\
\hline $100 \mathrm{I}$ & $\mathrm{N} \mathrm{M} \mathrm{H}$ & $\mathrm{M}$ & 55 & 2 & 4 & 2 & 7 & 8 & 9 & 9 & 9 & 9 & 15 \\
\hline \multicolumn{9}{|c|}{ Total number of participants } & \multicolumn{5}{|c|}{100 (50 males and 50 females $)$} \\
\hline \multicolumn{9}{|c|}{ Mean of ages } & \multicolumn{5}{|c|}{43.94} \\
\hline \multicolumn{9}{|c|}{ Total of scores } & \multicolumn{5}{|c|}{6898} \\
\hline \multicolumn{9}{|c|}{ Mean and level of telling time's scores } & \multicolumn{5}{|c|}{3.26 (Level 3) } \\
\hline \multicolumn{9}{|c|}{ Mean and level of counting money's scores } & \multicolumn{5}{|c|}{2.1 (Level 3) } \\
\hline \multicolumn{9}{|c|}{ Mean and level of addressing an envelope's scores } & \multicolumn{5}{|c|}{2.7 (Level 3) } \\
\hline \multicolumn{9}{|c|}{ Mean and level of solving daily math problems' scores } & \multicolumn{5}{|c|}{3.01 (Level 3) } \\
\hline \multicolumn{9}{|c|}{$\begin{array}{l}\text { Mean and level of writing a check and balancing } \\
\text { a checkbook's scores }\end{array}$} & \multicolumn{5}{|c|}{$8.12($ Level 1) } \\
\hline \multicolumn{9}{|c|}{ Mean and level of understanding medicine labels' scores } & \multicolumn{5}{|c|}{8.7 (Level 2) } \\
\hline \multicolumn{9}{|c|}{ Mean and level of using a calendar's scores } & \multicolumn{5}{|c|}{8.92 (Level 1) } \\
\hline \multicolumn{9}{|c|}{ Mean and level of reading instructions' scores } & \multicolumn{5}{|c|}{8.79 (Level 1) } \\
\hline \multicolumn{9}{|c|}{ Mean and level of using the telephone's scores } & \multicolumn{5}{|c|}{$9.2($ Level 1) } \\
\hline \multicolumn{9}{|c|}{ Mean and level of writing a phone message's scores } & \multicolumn{5}{|c|}{14.18 (Level 2) } \\
\hline \multicolumn{9}{|c|}{ General mean of number correct } & \multicolumn{5}{|c|}{6.898} \\
\hline \multicolumn{9}{|c|}{ General mean of independent functioning rating (levels) } & \multicolumn{5}{|c|}{2} \\
\hline \multicolumn{9}{|c|}{ Hypothetical mean } & \multicolumn{5}{|c|}{689.8} \\
\hline
\end{tabular}

The researchers conducted a literature review of various language tests' studies, published between January 2000 and June 2013, reporting on the effects of these tests in the assessment of language tasks. In the absence of any ALFA test studies in the Arab world, this review was supplemented by original data analyses focusing on the performance of aphasics, taking into consideration sex-by-diagnosis interactions on patterns of brain activation obtained during tasks of working memory, incentive decision-making, and facial affect processing. Compared with their performance in the posttest, the performance of the participating subjects in the pre-test shows sharp increase (6993 vs. 6898). This increase is not only limited to the total scores of the participating subjects in all subsets, it extends to include means of each subset's scores, levels and hypothetical mean. Compare:

\begin{tabular}{|c|c|c|}
\hline Item & Pre-test & Posttest \\
\hline Mean and level of telling time's scores & 6.9 (Level 2) & 3.26 (Level 3) \\
\hline Mean and level of counting money's scores & $6.98($ Level 2) & 2.1 (Level 3) \\
\hline Mean and level of addressing an envelope's scores & 6.03 (Level 2) & 2.7 (Level 3) \\
\hline Mean and level of solving daily math problems' scores & $5.66($ Level 2) & 3.01 (Level 3) \\
\hline ean and level of writing a check and balancing checkbook's scor & 5.97 (Level 2) & 8.12 (Level 1) \\
\hline
\end{tabular}




\begin{tabular}{|c|c|c|}
\hline Mean and level of understanding medicine labels' scores & 5.62 (Level 2) & 8.7 (Level 2) \\
\hline Mean and level of using a calendar's scores & $5.64($ Level 2) & 8.92 (Level 1) \\
\hline Mean and level of reading instructions' scores & $6.54($ Level 2) & 8.79 (Level 1) \\
\hline Mean and level of using the telephone's scores & $5.12($ Level 3) & 9.2 (Level 1) \\
\hline Mean and level of writing a phone message's scores & 10.95 (Level 3) & 14.18 (Level 2) \\
\hline General mean of number correct & 6.541 & 6.898 \\
\hline General mean of independent functioning rating (levels) & 2.1 & 2 \\
\hline Hypothetical mean & 699.3 & 689.8 \\
\hline
\end{tabular}

\begin{tabular}{|c|c|c|c|c|}
\hline \multirow{3}{*}{ Subsets } & \multicolumn{4}{|c|}{ Total and mean of scores } \\
\hline & \multicolumn{2}{|c|}{ Pre-test } & \multicolumn{2}{|c|}{ Posttest } \\
\hline & Males & Females & Males & Females \\
\hline Subset 1 & 352 & 333 & 173 & 153 \\
\hline Mean of subset 1 scores & 35.2 & 33.3 & 17.3 & 15.3 \\
\hline Subset 2 & 307 & 290 & 111 & 99 \\
\hline Mean of subset 2 scores & 30.7 & 29.0 & 11.1 & 9.9 \\
\hline Subset 3 & 325 & 282 & 121 & 149 \\
\hline Mean of subset 3 scores & 32.5 & 28.2 & 12.1 & 14.9 \\
\hline Subset 4 & 326 & 336 & 149 & 152 \\
\hline Mean of subset 4 scores & 32.6 & 33.6 & 14.9 & 15.2 \\
\hline Subset 5 & 321 & 280 & 410 & 402 \\
\hline Mean of subset 5 scores & 32.1 & 28.0 & 41.0 & 40.2 \\
\hline Subset 6 & 290 & 273 & 438 & 432 \\
\hline Mean of subset 6 scores & 29.0 & 27.3 & 43.8 & 43.2 \\
\hline Subset 7 & 269 & 288 & 441 & 451 \\
\hline Mean of subset 7 scores & 26.9 & 28.8 & 44.1 & 45.1 \\
\hline Subset 8 & 323 & 331 & 435 & 444 \\
\hline Mean of subset 8 scores & 32.3 & 33.1 & 43.5 & 44.4 \\
\hline Subset 9 & 236 & 283 & 457 & 463 \\
\hline Mean of subset 9 scores & 23.6 & 28.3 & 45.7 & 46.3 \\
\hline Subset 10 & 575 & 560 & 712 & 706 \\
\hline Mean of subset 10 scores & 57.5 & 56.0 & 71.2 & 70.6 \\
\hline
\end{tabular}

\section{Conclusion}

The researchers found a strong support for the validity and reliability of ALFA test. Evidence regarding all types of aphasic diseases is limited, but points to complex interactions between sex and diagnosis with therapeutic and pathological factors within impaired regions. Gender-by-diagnosis interactions were noted in the scores of the tests which reflect the general performance of the subjects under investigation. Such outcomes indicate a potential 
sex-by-diagnosis interaction influencing the performance of the patient to respond to the treatment. Our data suggest that the test is valid and reliable; therefore, is recommended to be used for Arab aphasics of both sexes. The following figure summarizes this result. Consider:

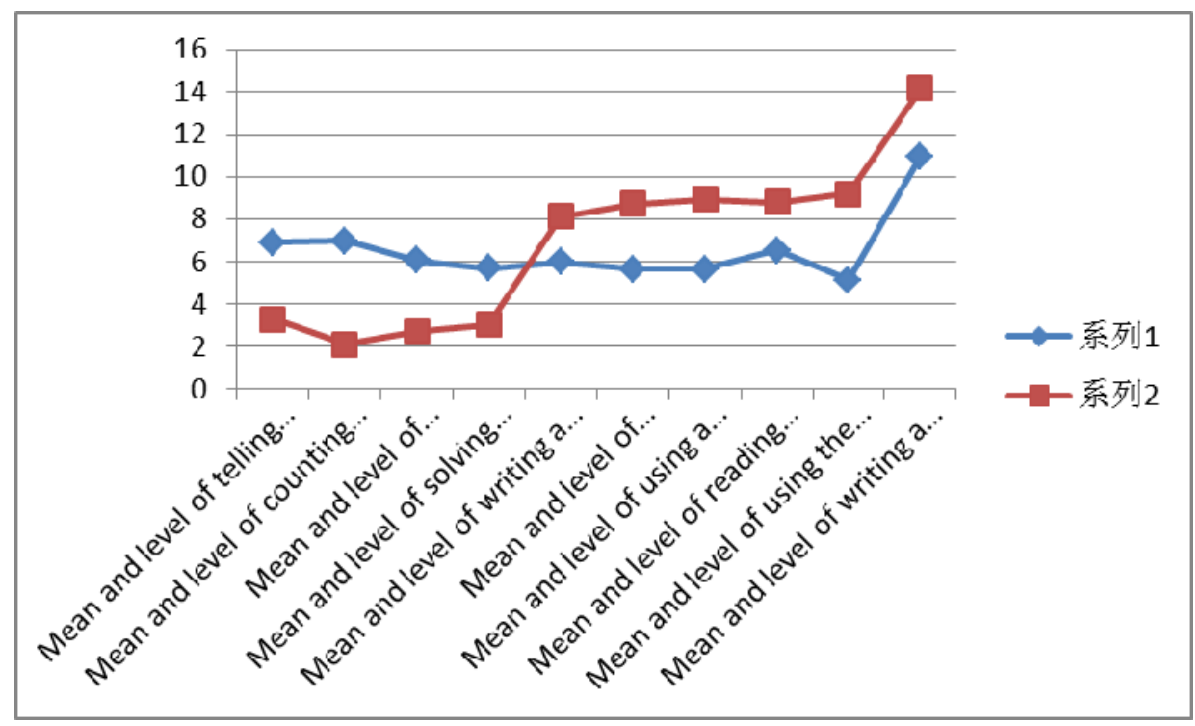

\section{References}

Allen, D., Thaler, N., Barchard, K., Vertinski, M., \& Mayfield, J. (2012). Factor structure of the Comprehensive Trail Making Test in children and adolescents with brain dysfunction. Psychological Assessment, 24(4), 964-972. http://dx.doi.org/10.1037/a0028521.

Al-Yaari, S., \& Almaflehi, N. (2013). Effects of Auditory Brainstem Response (ABR) on Measuring Children's Auditory Functions: An Experimental Investigation . In press, 1-17.

Attard, M., Rose, M. L., \& Lanyon, L. (2013). The comparative effects of Multi-Modality Aphasia Therapy and Constraint-Induced Aphasia Therapy-Plus for severe chronic Broca's aphasia: An in-depth pilot study. Aphasiology, 27(1), 80-111. http://dx.doi.org/10.1080/02687038.2012.725242.

Below, J. L., Skinner, C. H., Fearrington, J. Y., \& Sorrell, C. A. (2010). Gender Differences in Early Literacy: Analysis of Kindergarten through Fifth-Grade Dynamic Indicators of Basic Early Literacy Skills Probes. School Psychology Review, 39(2), 240-257.

Block, K., Amie, A., Chery, J., Gina, N., Peggy, A., Deborah, W., \& Sara, H. (1993). "Definitions of Communication Disorders and Variations", Ad Hoc Committee on Service Delivery in the Schools. ASHA, 13-14. http://dx.doi.org/10.1044/policy. RP1993-00208, retrieved 2010-08-07.

Boonstra, A., Reneman, M., Stewart, R., \& Balk, G. (2012). Life satisfaction questionnaire (Lisat-9): reliability and validity for patients with acquired brain injury. International Journal Of Rehabilitation Research, 35(2), 153-160. 
Brogden, L. (2008). Language and gender: An advanced resource book. Canadian Journal Of Applied Linguistics, 11(2), 121-123.

Cobley, C., Thomas, S., Lincoln, N., \& Walker, M. (2012). The assessment of low mood in stroke patients with aphasia: reliability and validity of the 10-item Hospital version of the Stroke Aphasic Depression Questionnaire (SADQH-10). Clinical Rehabilitation, 26(4), 372-381. http://dx.doi.org/10.1177/0269215511422388.

Eggermont, J. J., Burkard, R. F., \& Manuel, D. (2007). Auditory evoked potentials: basic principles and clinical application. Hagerstwon, MD: Lippincott Williams \& Wilkins, p. 3. ISBN 0-7817-5756-8. OCLC 70051359.

Hurkmans, J., Jonkers, R., Boonstra, A. M., Stewart, R. E., \& Reinders-Messelink, H. A. (2012). Assessing the treatment effects in apraxia of speech: introduction and evaluation of the Modified Diadochokinesis Test. International Journal Of Language \& Communication Disorders, 47(4), 427-436. Http://dx.doi.org/ 10.1111-1460-6984. 2012.00155x.

Marshall, J., Best, W., Cocks, N., Cruice, M., Pring, T., Bulcock, G., \& Cautea, A. (2012). Gesture and Naming Therapy for People With Severe Aphasia: A Group Study. Journal Of Speech, Language \& Hearing Research, 55(3), 726-738. http://dx.doi.org/10.1044/1092-4388(20122)/11-0219.

Marshall, N., Herens, J., \& Goldstein, C. (2011). Mothers and Their Retarded Children VS Mothers and Their Nonretarded Children. Am. J. Mental Def., 415-419.

Neisser, U. (1997). "Rising Scores on Intelligence Tests". American Scientist, 85, 440-447.

Okubo, P., Fábio, S., Domenis, D., \& Takayanagui, O. (2012). Using the National Institute of Health Stroke Scale to predict dysphagia in acute ischemic stroke. Cerebrovascular Diseases (Basel, Switzerland), 33(6), 501-507. http://dx.doi.org/10.1159/000336240.

Philibert, B., Durrant, J., Ferber-Viart, C., Duclaux, R., Veuillet, E., \& Collet, L. (2003). Stacked tone-burst-evoked auditory brainstem response (ABR): preliminary findings. International Journal Of Audiology, 42(2), 71-81.

Rehman, T., Ali, R., \& Yonas, H. (2008). "Rapid progression of traumatic bifrontal contusions to transtentorial herniation: A case report. Cases Journal, 1-7.

Skeppholm, M., Ingebro, C., Engström, T., \& Olerud, C. (2012). The Dysphagia Short Questionnaire: an instrument for evaluation of dysphagia: a validation study with 12 months' follow-up after anterior cervical spine surgery. Spine [Spine (Phila Pa 1976)] 2012 May 15; Vol. 37(11), pp. 996-1002. http://dx.doi.org/ 10.1097/BRS.0b013e31823a7a5b.

Sutcliffe, L., \& Lincoln, N. (1998 Dec;12(6)). The assessment of depression in aphasic stroke patients: the development of the Stroke Aphasic Depression Questionnaire. Clin Rehabil, 506-13.

von-Steinbuechel, N., Wilson, L., Gibbons, H., Muehlan, H., Schmidt, H., Schmidt, S., . . . Zitnay, G. (2012). QOLIBRI overall scale: a brief index of health-related quality of life after 
traumatic brain injury. Journal Of Neurology, Neurosurgery, And Psychiatry [J Neurol Neurosurg Psychiatry] 2012 Nov; Vol. 83 (11), pp. 1041-7.

\section{Glossary}

ABR (Auditory Brainstem Response) It is a neurologic test of auditory brainstem function in response to auditory (click) stimuli. First described by Jewett and Williston in 1971, ABR audiometry is the most common application of auditory evoked responses. The resulting recording is a series of vertex positive waves of which I through $\mathrm{V}$ are evaluated. These waves, labeled with roman numerals in Jewett and Williston convention, occur in the first 10 milliseconds after onset of an auditory stimulus. ABR is a helpful tool in determining a child's ability to hear. The test uses a special computer to measure the way the child's hearing nerve responds to different sounds (Eggermont, et al., 2007: p. 3).

ALFA (Communication Activities of Daily Living, Second Edition) The test assesses the functional communication skills of adults with neurogenic communication disorders. The ALFA is given individually in about 30 minutes and contains 50 test items that assess communication activities in seven areas: Reading, writing, and using numbers; Social interaction; Divergent communication; Contextual communication; Nonverbal communication; Sequential relationships; and Humor/metaphor/absurdity. Original CADL items that required role playing, use of an audiocassette for identification of environmental sounds, and certain props were eliminated to ease test administration and reduce total test time.

The updated norming sample included 175 adults with neurogenic communication disorders resulting primarily from left- or right-hemisphere stroke or traumatic brain injury. Level of care spanned the full continuum of acute care to sub-acute, long-term, home, and outpatient care. The sample was stratified to approximate the 1997Statistical Abstract of the United States (U.S. Bureau of the Census). Reliability coefficients were: .93 coefficient alpha, .85 test-retest, and .99 inter-scorer. The ALFA also was found to be valid as a functional communication test for adult neurogenic populations. Complete ALFA Kit includes: Examiner's Manual, Picture Book, 25 Examiner Record Booklets, and 25 Patient Response Forms, all in a sturdy storage box (http:/www.proedinc.com/ customer/ ProductView.aspx?ID=1533\&sSearchWord=).

DSQ (Dysphagia Short Questionnaire) This questionnaire is considered to be a validated tool for the assessment of dysphagia in anterior cervical spine surgery patients (Skeppholm, et al., 2012: pp.996-1002).

IQ (intelligence quotient) It is a score derived from one of several standardized tests designed to assess intelligence. The abbreviation "IQ" comes from the German term Intelligenz-Quotient, originally coined by psychologist William Stern. When modern IQ tests are devised, the mean (average) score within an age group is set to 100 and the standard deviation (SD) almost always to 15 ( Neisser, 1997: pp. 440-447).

QOLIBRI (Quality of Life after Brain Injury) is the first instrument specifically developed to assess health-related quality of life (HRQoL) of individuals after traumatic brain injury. 
Disease or condition-specific HRQoL instruments are assumed to be more sensitive to particular health conditions and therefore give more focused and more precise information than generic ones (http://www.qolibrinet.com/).

SADQ (Stroke Aphasic Depression Questionnaire) This questionnaire was developed to assess the depression in aphasic stroke patients. It is a 21-item questionnaire developed based on observable behaviors thought to be associated with depressed mood. It is completed by the client's caregiver on behalf of the client (Sutcliffe \& Lincoln, 1998: pp. 506-513).

SLP/Ts (Speech-Language Pathologists/ Therapists) They are specialized in communication disorders as well as swallowing disorders. They are also called Speech Pathologists (Block et al., 1993: p. 23)

TBI (Traumatic Brain Injury) It occurs when an external force traumatically injures the brain. TBI can result when the head suddenly and violently hits an object, or when an object pierces the skull and enters brain tissue (Rehman et al., 2008: pp.1-7).

\section{Copyright Disclaimer}

Copyright reserved by the author(s).

This article is an open-access article distributed under the terms and conditions of the Creative Commons Attribution license (http://creativecommons.org/licenses/by/3.0/). 